\title{
PROFISSIONAIS DE SAÚDE NA CONTEMPORANEIDADE
}

\author{
Mônica Ramos Daltro Mestre em Saúde Humana. Professora e Coordenadora \\ do Curso de Psicologia da Escola Bahiana de Medicina \\ e Saúde Pública \\ Ligia Marques Vilas Bôas Pedagoga da Escola Bahiana de Medicina e Saúde \\ Pública
}

\section{Carlos Alberto Ferreira Danon Licenciado em Ciências Sociais. Professor da Escola} Bahiana de Medicina e Saúde Pública

\begin{abstract}
Resumo
O texto apresenta o panorama estrutural e teórico do Projeto Político Pedagógico do Curso de Psicologia da Escola Bahiana de Medicina e Saúde Pública. Tem como documento referencial as Diretrizes Curriculares Nacionais para formação em psicologia publicada pelo Ministério da Educação, em 2004. Propõe como concepção pedagógica a substituição da organização curricular arrolada em disciplinas para a construção de um currículo fundamentado em competências e habilidades profissionais. Entende como princípio fundante o currículo alicerçado na interdisiplinaridade, voltado para o desenvolvimento de competência. Foca o sujeito do aprendizado como ator central do processo pedagógico; considera e sinaliza a ampliação do campo profissional do psicólogo em novos contextos, como nas áreas social, jurídica e esportiva, consolidando a profissão como um amplo espaço de responsabilidade social. Entende que, na contemporaneidade, o psicólogo revela-se como um profissional de saúde. Assim, o processo formativo tem como desafio apartar-se do modelo tradicional de ensino biomédico e preparar profissionais para lidar com a saúde como fenômeno complexo, multirreferencializado, que envolve aspectos socioculturais, históricos, subjetivos.
\end{abstract}

Palavras Chave: Projeto político pedagógico; Psicologia; Currículo.

\section{HEALTH PROFESSIONALS IN CONTEMPORANEITY}

\begin{abstract}
The paper presents the structural and theoretical overview the Pedagogic Political Project of the Psychology Course of Escola Bahiana de Medicina e Saúde Pública (Bahia School of Medicine and Public Health). It has as reference document the National Curriculum for education in Psychology published by the Ministry of Education in 2004. It proposes as instructional design the replacement of curricular organization mustered in disciplines for building a curriculum based on competencies and professional skills. Understands as foundational principle the curriculum grounded in interdisciplinarity, focused on the development of competence. Focuses on the subject of learning as central actor of the educational process; considers and signals the expansion of the professional field of the psychologist in new contexts, as in the social, legal and sports, consolidating the profession as a broad area of social responsibility. Considers that, in contemporary times, the psychologist reveals itself as a health professional. Thus, the learning process is challenged to depart from the traditional model of biomedical teaching and to prepare professionals to deal with health as a complex phenomenon, multi-referentialized, that involves socio-cultural, historical and subjective aspects.
\end{abstract}

Keywords: Political pedagogical project; Psychology; Curriculum. 


\section{INTRODUÇÃO}

Em 2004, o Conselho Nacional de Educação do Ministério da Educação (MEC) aprova as novas Diretrizes Curriculares Nacionais (DCNs) para os cursos de Psicologia ${ }^{(1)}$ e propõe a substituição do currículo com base em enunciados de disciplinas e conteúdos por um currículo fundamentado no desenvolvimento de competências e habilidades profissionais. ${ }^{(2)}$ As DCNs permitiram uma maior liberdade aos cursos de graduação para ajustar seus currículos à diversidade teórica e de atuação da Psicologia Contemporânea, considerando inclusive as demandas regionais onde os cursos se inserem.

O currículo por competência foca o sujeito do aprendizado como ator central do processo pedagógico. Assim, a construção do conhecimento não se limita à transmissão de conteúdos disciplinares, mas tem como princípio a aplicabilidade do que foi aprendido. ${ }^{(3)}$

A ampliação do campo profissional do psicólogo em novos contextos, como nas áreas social, jurídica e esportiva consolidam a profissão como um amplo espaço de responsabilidade social. Ainda que a Psicologia Clínica continue sendo a referência mais tradicional de identidade, seja pelos leigos, seja para os próprios profissionais, a Psicologia assumiu novas faces, aumentou sua inserção no mercado de trabalho e com expressiva representatividade no campo da Psicologia da Saúde. ${ }^{(1)}$

Tradicionalmente, a Psicologia identificada como da saúde, constituía-se e se confundia como o campo de atuação da clínica privada. ${ }^{(4)}$ A emergência da Psicologia Hospitalar também reivindica para si esse campo. Na mesma direção, a Psicologia Social contemporânea, pleiteia a "saúde" como parte de seu campo de atuação profissional, por entender a saúde como um fenômeno psicossocial, datado historicamente. ${ }^{(4)}$ Para esses autores, ser psicólogo da saúde significa, hoje, ocupar um lugar de atuação marcado pela diversidade, portanto própria da Psicologia Social.

Este texto apresenta uma proposta curricular de graduação, referenciada nas DCNs, ou seja, fundamentada no desenvolvimento de competências para uma atuação profissional generalista. Para isso, leva em conta o caráter dinâmico de uma ciência em permanente construção e reconfiguração que é a Psicologia, assim como sua natureza híbrida, originada de distintos campos de saberes. ${ }^{(4)}$ Entretanto, considera que independe do campo de 
atuação/contexto ou da abordagem teórica adotada, cabendo ao psicólogo promover saúde e qualidade de vida dos indivíduos e organizações em que esteja inserido, sempre considerando a perspectiva dos Direitos Humanos.

No Brasil, a concepção biomédica de saúde como ausência de doença tem norteado as ações formativas dos profissionais de saúde, a partir de uma perspectiva filosófica individualista e adaptativa, ${ }^{(5)}$ excluindo a subjetividade e o contexto cultural como elementos pertinentes à prática profissional. ${ }^{(6)}$

O entendimento contemporâneo do psicólogo como profissional de saúde coloca, para o processo formativo, o desafio de apartar-se do modelo tradicional de ensino biomédico e preparar profissionais para dar conta de lidar com a saúde como fenômeno complexo, multirreferencializado, que envolve aspectos socioculturais, históricos, subjetivos, simultaneamente emoldurando uma teia complexa de relações que se irtercruzam em uma dinâmica de harmonia e conflito paralelamente contínuos.

Na década de 1980, novos modelos de ensino começam a ser propostos a partir da percepção de saúde-doença como um processo. Como alternativa ao modelo tradicional biomédico, surge o da formação ético-humanista, fundamentado em uma perspectiva intersetorial da saúde. ${ }^{(5)}$ Esse paradigma, coerente com os princípios da Organização Mundial da Saúde ${ }^{(7)}$ (OMS - 1984) compreende a saúde como estado de bem-estar físico, mental, social e espiritual e põe em evidência o ser humano em suas múltiplas dimensões. Nessa perspectiva, a subjetividade ganha relevância no processo de formação do profissional de saúde A escuta do sujeito, pertencente a uma complexidade cultural que engendra relações para a compreensão das representações de saúde-doença, ganha espaço na construção dos processos formativos. A fronteira da lógica disciplinar está permanentemente transversalizada por saberes tecidos em uma dinâmica que constrói e reconstrói o sujeito em uma rede plural de significados.

As DCNs, conforme estão estruturadas legalmente, fortalecem essa perspectiva éticohumanista. Ao propor o desenvolvimento de currículos com base em habilidades e competências permite à sociedade discutir o campo de formação profissional a partir de múltiplos saberes, ${ }^{(8)}$ assim como fundamenta a proposta curricular, filosófica e epistemológica em referenciais que preparem o profissional de saúde para atuar de forma crítica e a refletir sobre os aspectos objetivos e subjetivos que envolvem a existência humana. Consideram, assim, a complexidade de 
realidades, ambiente que relaciona, ao mesmo tempo, contradições e ambivalências em uma trama de poder que negocia e conflitua tensões.

\section{NOVOS PARADIGMAS PARA FORMAÇÃO DO PSICÓLOGO}

Os objetivos educacionais do Projeto Pedagógico do curso de Psicologia da EBMSP estão relacionados com os novos paradigmas da educação do profissional de saúde e buscam o desenvolvimento de competências técnicas, humanas e éticas, de forma que o sujeito possa reconhecer e lidar com os aspectos físicos, sociais e subjetivos envolvidos no processo saúdedoença. Assim, identifica os modos de aprender mais impregnantes na contemporaneidade. Propõe estratégias educativas que equilibrem a construção do conhecimento científico e humano com o desenvolvimento de habilidades e atitudes voltadas para a prática profissional. ${ }^{(9)}$

O currículo de Psicologia da Bahiana fundamenta-se em uma concepção que põe em relevo a formação de um profissional qualificado para atuar como promotor de saúde um psicólogo apto a atuar na assistência, prevenção e no desenvolvimento das potencialidades de vida dos sujeitos $^{(10)}$ ou das organizações.

A formação de psicólogos competentes na promoção da saúde e da qualidade de vida, na perspectiva dos direitos humanos, requer a estruturação de um currículo plural, que garanta uma atuação generalista. A noção de generalidade não nega a especialização, ao contrário relaciona-se com o sentido de complexidade que a contemporaneidade engendra e o sujeito compõe. Nessa ótica, a generalidade abre um campo de análise amplo, multifacetado e interdisciplinar para atuação do psicólogo, sem prejuízo para a especialização, não raro necessária para aprofundamento e análise de questões mais específicas.

Para viabilizar a realização desse objetivo, NININ, (2008) recomenda que o currículo esteja organizado de forma a associar competências e habilidades aos quatro pilares básicos para a educação no século XXI, definidos pela $\mathrm{UNESCO}^{(12)}$ :

a) Aprender a conhecer - dominar o conhecimento de forma a compreender o mundo para viver dignamente, desenvolver-se profissionalmente e comunicar-se;

b) Aprender a fazer - a capacidade de resolver conflitos, adquirir competências que tornem alunos e professores aptos a enfrentar novas situações; 
c) Aprender a ser - é a capacidade de autonomia e julgamento cônscios da responsabilidade social;

d) Aprender a conviver - desenvolvendo a consciência sobre o outro, sua história, sua tradição, sua espiritualidade. É aceitar o outro com suas diferenças e singularidades. É ser capaz de realizar projetos comuns.

O objeto da Psicologia, em toda a sua diversidade constitui-se um elemento complicador. Cruz e Schultz ${ }^{(13)}$ em um estudo sobre avaliação de competências profissionais e formação de psicólogos, afirmam que, para os estudantes, o principal problema enfrentado no processo de formação é a forma como esse objeto é apresentado, pois, de modo geral, faz-se de maneira fragmentada, com uma especial supervalorização do conhecimento teórico-conceitual, em detrimento do conhecimento prático. Além disso, historicamente, o ensino superior vem repetindo a lógica do professor especialista detentor do saber/poder que coloca o aluno como um depositário de conteúdos a serem reproduzidos, sem, necessariamente, estabelecer um compromisso com uma aprendizagem contextualizada e significativa.

Entretanto, uma nova ordem se instala no mundo contemporâneo. Hoje, a produção de novos conhecimentos é veloz e sua socialização tece redes, a cada dia, mais complexas. O acesso à diversidade de conteúdos relativos às mais diferentes áreas do conhecimento não apresenta obstáculos, principalmente, com o advento das novas tecnologias da informação. O desafio constitui-se em desenvolver competências. Para Perrenoud, ${ }^{(14)}$ uma competência está sempre associada à mobilização de saberes que não se aprisionam ao acúmulo do conhecimento, mas refere-se à virtualização de uma ação, à capacidade de recorrer ao que se sabe, para se realizar o que se deseja.

Além disso, a geração de jovens que hoje ingressam no ensino superior, denominada geração Y é, segundo Amorim, ${ }^{(15)}$ um grande desafio para as instituições de ensino, pois apresentam um padrão de organização mental muito distante do modelo de ensino-aprendizagem, fundamentado na transmissão de conteúdo/informações. A geração Y, em grande parte, é tecnológica, seus valores são impregnados por referenciais narcisistas, individualistas e imagéticos. Ao processo formativo cabe o desenvolvimento de competências necessárias para 
transformar essa informação em construções sociais que ultrapassem seus próprios interesses identificando sentido, em curto prazo, nas coisas que realiza. ${ }^{(15)}$

A construção do Projeto Pedagógico do curso de Psicologia da EBMSP circunscreve como objeto de seu estudo, o Ser Humano, subjetivado, concreto, biológico, que possui um locus espaço-temporal e se constitui entre o individual e o coletivo. É nessa perspectiva que o PPP apresentado busca acompanhar o movimento de transformação pelo qual passa a Psicologia no Brasil, incorporando uma proposta pedagógica inovadora, que motiva o estudante a aprender a conviver, a aprender a ser, a aprender a aprender e aprender a fazer no tornar-se psicólogo, sempre atento ao compromisso com o outro e com o autocuidado.

Esse currículo foi construído coletivamente a partir de um processo dialógico, que envolveu a participação de estudantes, professores e colaboradores do curso. Estrutura-se a partir da concepção de competência como mobilização de saberes, propõe, então, o uso de metodologias ativas de aprendizagem, focalizando a interação entre teoria-prática e o desenvolvimento de valores, como a ética, a solidariedade, o humanismo.

\section{O CURSO DE PSICOLOGIA DA EBMSP}

O curso de Psicologia da BAHIANA tem 12 anos de prestação de serviço à comunidade e já formou aproximadamente 900 psicólogos. O curso está vinculado à Fundação Bahiana para o Desenvolvimentos das Ciências, que se dedica há 60 anos à formação de profissionais de saúde. Trata-se de um curso diurno, que oferece 100 vagas anuais. Desde 2010, o curso organiza sua estrutura curricular a partir de componentes curriculares organizados em eixos temáticos, distribuídos ao longo de 10 semestres letivos que totalizam uma carga horária de 4.018 horas, sendo 2.502 de aulas teóricas, 576 de atividades práticas interdisciplinares, 720 de estágio e 220 correspondentes a atividades complementares, tendo Libras como disciplina optativa. Objetiva formar psicólogos a partir de valores éticos e humanistas, cidadãs e cidadãos, que atuem como agentes transformadores na construção de uma sociedade mais democrática e menos desigual, trabalhando com seres humanos nas dimensões psicossocial, psicodinâmica, institucional e comunitária. 
Sua estrutura curricular multirreferencializada trabalha com teorias divergentes e convergentes, desenvolvida com base em ideais humanistas, construtivistas e sóciointeracionistas, que colocam o conhecimento a serviço da formação do ser humano e da sociedade. O processo formativo contemporâneo precisa estar focado no desenvolvimento da autonomia do estudante e simultaneamente do professor; para tanto, compreende o estudante sujeito da aprendizagem - como construtor de seu próprio conhecimento e o professor como mediador da relação ensino-aprendizagem.

A experiência curricular proposta focaliza o aprender-a-refletir-fazendo. Trata-se de uma visão teórico-prática e interdisciplinar sobre a experiência de aprender e ensinar. No trajeto da formação do psicólogo, o diálogo do docente e discente com diferentes teorias e diferentes lócus de atenção à saúde e, mais especificamente, ao fenômeno psicológico. Propõe o desenvolvimento de competências que exigem formas complexas de mobilização do conhecimento como as capacidades de expressar-se com clareza, utilizando-se de diferentes linguagens; de tomar decisões; de enfrentar situações-problema, de debater e defender uma posição; de lidar com as diferenças utilizando o princípio da equidade. Ao professor, ator nesse processo, cabe o papel de mediador, daquele que desafia o aprendente a conhecer a Psicologia de forma contextualizada na saúde e no universo do trabalho.

O exercício de formação do psicólogo prioriza a inserção do aluno em diversas comunidades de ação pedagógica voltada para a observação, pesquisa e ação do trabalho em Psicologia. As atividades ocorrem sob a orientação de um docente que estabelece a mediação entre o trabalho e os sujeitos sociais pertencentes às comunidades. Caracteriza-se como uma ação acadêmica que associa as dimensões técnica, política e cultural. Uma vez que a experiência ocorre em um lugar com identidade própria, requer um olhar mais do que técnico para a compreensão da cena conjuntural. A formação empírica necessita da construção de uma atitude que perceba a cultura em dimensão ampla e diversa, buscando no processo de formação atitudes de compreensão e respeito para a coexistência com a diversidade. Nessa perspectiva, a formação do psicólogo como profissional de saúde não se isola em uma rede tecnicista, ao contrário, inserese em um campo aberto que percebe o sujeito em sua dimensão integral, em especial, sua condição psicossocial e histórica. Essa posição implica no entendimento de uma Psicologia como elemento promotor de saúde. Assim, a proposta pedagógica se efetiva no desenvolvimento de 
competências atitudinais, conceituais e procedimentais, identificadas como necessárias à atuação do psicólogo, que são aqui descritas de acordo com as DCNs para a formação em Psicologia, associadas às perspectivas educacionais propostas pela UNESCO:

a) Perceber os próprios limites individuais e profissionais;

b) Realizar autocuidado, zelando pela sua saúde física, mental e seu bem-estar como cidadão e profissional, inclusive gerenciando e valorizando sua carreira;

c) Comunicar-se consigo e com o outro, administrando as próprias emoções e sentimentos, desenvolvendo relações interpessoais e intergrupais adequadas ao paciente, à família, à instituição e à equipe multiprofissional;

d) Adaptar-se às mudanças e constantes transformações dos cenários;

e) Aprender a aprender continuamente, buscando oportunidades e aproveitando as demandas da contemporaneidade.

f) Lidar criticamente com o conhecimento, com a dinâmica do mercado de trabalho e as políticas de saúde, tomando decisões coerentes e consequentes, a partir das habilidades de avaliar, sistematizar e decidir pela condição mais apropriada de atendimento, acompanhamento à formação dos sujeitos ou grupos envolvidos;

g) Promover ações de saúde, prevenindo agravos e danos na comunidade, na família, no trabalho e no indivíduo;

h) Compreender as múltiplas determinações dos seres humanos e consequentemente do processo saúde-doença;

i) Entender como se constrói o universo simbólico e como se constitui o fenômeno psicológico;

j) Compreender a sociedade como uma rede de significados simbólicos e conhecer os direitos humanos;

k) Conhecer o Sistema Único de Saúde e os distintos campos de atuação do psicólogo;

1) Compreender a Psicologia como instituição social necessária ao desenvolvimento da sociedade; 
m) Compreender o significado da promoção da saúde de forma a identificar o psicólogo nesse contexto;

n) Trabalhar em equipe, com capacidade para tomar decisões, atuar como líder e se comunicar com habilidade;

o) Gerenciar e administrar recursos humanos, físicos, materiais, assim como informações;

p) Realizar pesquisas no campo da Psicologia e da Saúde Pública;

q) Analisar o campo de atuação profissional de forma crítica, incluindo os desafios contemporâneos

r) Identificar as demandas de natureza psicológica, diagnosticar, elaborar projetos, planejar, registrar dados de forma coerente com os referenciais teóricos e as peculiaridades da população atendida;

s) Selecionar e utilizar instrumentos e procedimentos para coleta de dados de forma apropriada e ética;

t) Planejar e conduzir observações e entrevistas em diferentes contextos e considerar as singularidades envolvidas;

u) Coordenar e manejar grupos em diferentes contextos e com diferentes populações;

v) Elaborar relatórios científicos, pareceres técnicos, laudos psicológicos e outras comunicações profissionais de maneira ética e coerente com as circunstâncias e contextos;

w) Atuar em equipes inter e multiprofissionais;

x) Escutar as distintas expressões da subjetividade sempre atento(a) ao contexto sociohistórico;

y) Levantar informações bibliográficas em indexadores, periódicos, livros, manuais técnicos e outras fontes que garantam a educação permanente, o manejo e a produção do conhecimento científico.

A abordagem contempla o desenvolvimento dessas competências. Ao longo do curso, privilegia-se a interação contínua da teoria com a prática. Essa proposta considera a experiência prática, desde o primeiro semestre da graduação, através de atividades de observação, realização 
de cursos com temas específicos para pequenos grupos. Essas ações pedagógicas são sempre acompanhadas pelos docentes responsáveis nos diferentes componentes curriculares. A partir dessas experiências, o estudante, em diálogo com o professor, elabora o sentido da aprendizagem em construção, ao tempo em que desenvolve, gradualmente, as competências e as habilidades necessárias para ser psicólogo apto a responder às demandas de diferentes contextos e de compreender sua função de promotor de saúde e de qualidade de vida.

A formação em Psicologia proposta engloba componentes curriculares em um projeto educativo de caráter humanista centrada numa visão crítica-emancipatória, onde a autonomia intelectual, solidária e ética está sustentada por metodologias ativas e clássicas. Assim, o curso de Psicologia considera as demandas da contemporaneidade e busca enfrentar os desafios de:

a) relacionar a construção do saber à diversidade, superando o modelo de formação dominante que cria competição e preconceitos entre os distintos campos de conhecimento e atuação do psicólogo;

b) romper com uma proposta curricular fragmentada e buscar a implantação de um currículo integrado;

c) eleger metodologias que coloquem professor e aluno como parceiros e destaquem os quatro pilares da educação: aprender a conhecer; aprender a fazer; aprender a ser; aprender a conviver como cerne do processo formativo;

d) apresentar um saber teórico-prático organizado em torno de uma visão interdisciplinar e multiprofissional;

e) articular formação ética, científica e tecnológica em diferentes contextos sociais;

f) favorecer a construção de uma identidade pessoal e profissional madura de sujeitos dispostos a atuar como psicólogos:

g) estruturar uma prática pedagógica coerente como espaço de superação dos desafios supramencionados.

h) A articulação teoria-prática se efetiva no decorrer do curso, mediante o uso de técnicas de problematização, estudo de casos, bem como pela aplicação prática imediata e crítica dos conhecimentos adquiridos nas atividades interdisciplinares, que se realizam fundamentalmente no território do Distrito Sanitário de Brotas, 
mediante convênio já estabelecido, com a Secretaria de Saúde do Estado da Bahia (SESAB) e Secretaria Municipal de Saúde de Salvador (SMS). O bairro de Brotas é a segunda área mais populosa do município de Salvador, cuja população levantada é de 212.910 habitantes. ${ }^{(16)}$

A interdisciplinaridade assume um papel de relevância para a compreensão dos contextos educativos formativos, tanto no âmbito da teoria, como da prática, onde ocorrem os estágios curriculares. Além da construção de novos saberes, favorece que diferentes realidades sociais sejam evidenciadas na estrutura de poder vigente. Isso em razão da perspectiva interdisciplinar romper com o paradigma científico hegemônico, tradicional que departamentaliza o conhecimento e estabelece regras fronteiriças rígidas para a pesquisa acadêmica. A proposta interdisciplinar afirma-se pelo reconhecimento da complexidade que a sociedade engendra. Assim, os atores envolvidos no processo pedagógico estão em formação permanente para reconhecer e mediar as tensões, as ambivalências e as rede de solidariedade tecidas pelos diversos grupos sociais. Essas articulações se organizam em atividades de ensino-pesquisa-extensão e estão amparadas por um programa institucional próprio de subvenção de Monitoria e Iniciação Científica; e também inclui a parceria com a Fundação de Amparo à Pesquisa da Bahia (FAPESB). Nesse sistema também estão em processo de articulação projetos com a participação de estudantes de graduação e pós-graduação latu sensu no Serviço de Psicologia e stricto sensu no Programa de Medicina e Saúde Humana da EBMSP.

Dentre os princípios que orientam este currículo, pode-se destacar o espaço dado às metodologias ativas que colocam o aluno diante de desafios que o levem a pensar, produzir e construir o seu próprio conhecimento. Como exemplo, podemos enumerar a Aprendizagem Baseada em Problemas (ABP), o Estudo de Caso e as experiências de aprendizagem desenvolvidas pelos componentes curriculares do eixo Intervenções em Psicologia, que será descrito posteriormente.

O uso de metodologias ativas tem um destaque na proposta metodológica. Seu objetivo é facilitar ao estudante aprender a aprender, é motivá-lo a buscar as informações relevantes e necessárias à resolução de problemas que o desafiam para construção do conhecimento; estimular o desenvolvimento da habilidade de trabalhar em grupo, ressaltando a importância do estudo 
individual e permitindo o respeito ao interesse e ao ritmo de cada estudante. Essa metodologia considera o aprendizado centrado no aluno; o professor é facilitador da aprendizagem, que o avalia processualmente, estando sempre atento às respostas individuais e coletivas, nos planos cognitivos e atitudinais.

Nessa perspectiva, considera-se a contradição e o paradoxo como base analítica para a compreensão do processo de avaliação. A interdisciplinaridade, assim, estabelece comunicação com várias referências do conhecimento, tecendo uma ponte contínua entre os componentes curriculares que integralizam a graduação em Psicologia.

Os componentes curriculares de natureza teórica estão inter-relacionados ao longo dos semestres a partir de seis Eixos Temáticos, que abrangem diferentes teorias, áreas de conhecimento, métodos de investigação, intervenção e pesquisa em Psicologia.

A definição dos Eixos Temáticos viabiliza a gestão do conhecimento na organização das atividades didáticas e assegura o fluxo de temas transversais, como ética, registros em Psicologia, promoção de saúde, autocuidado, articulados de forma direta às teorias e práticas apresentadas. Relacionada à proposta acadêmica, os eixos também estabelecem diálogos temáticos e teóricos entre si, proporcionando uma visão interativa dos componentes disciplinares de cada semestre e do curso como um todo.

Para estabelecimento dos ganchos analíticos entre os eixos nos semestres, o regimento do curso organiza os Núcleos Curriculares, planejados semestralmente, que preveem o encontro regular dos professores para discutir as questões acadêmicas de cada semestre letivo. É colocada também a discussão ampliada dessas questões com os representantes discentes no Conselho de Série. Nesses encontros, são debatidos os processos de ensino-aprendizagem ao mesmo tempo em que se avalia o desenvolvimento do que foi planejado para o semestre letivo.

Os eixos estão assim delineados:

\section{Ser Humano e Ciclo de Vida;}

II. Fundamentos em Psicologia;

III. Psicologia Sociedade e Cultura;

IV. Intervenções em Psicologia;

V. Pesquisa em Psicologia; 


\section{Práticas Pré-Profissionalizantes}

EIXO I - Ser Humano e Ciclo de Vida

Estudo do ser humano nas diversas fases de sua existência, o que inclui a multideterminação do processo saúde-doença e especificamente do fenômeno psicológico. Inclusão e aprofundamento das diferentes teorias do desenvolvimento, a fisiologia, neurologia, genética e psicopatologia, sempre atentos aos diferentes contextos sociais.

Eixo II - Fundamentos em Psicologia

Estudo das bases epistemológicas da psicologia a partir de fundamentos históricos filosóficos, socioantropológicos e dos marcos teóricos da psicanálise indispensáveis à compreensão da psicologia como profissão.

Eixo III - Psicologia Sociedade e Cultura

Estudo do corpo teórico que embasa o campo da psicologia enquanto ciência e profissão, considerando a relação dialógica entre o ser humano, a cultura e o fenômeno psicológico.

Eixo IV - Intervenções em Psicologia

Estudo de diferentes técnicas e instrumentos de atuação do psicólogo que envolve modelos de observação, entrevista, manejo de grupo, avaliação psicológica em contextos de saúde e trabalho. Estudo das especificidades teóricas e técnicas psicoterápicas tradicionais e emergentes.

Eixo V - Pesquisa em Psicologia 
Estudo de métodos e técnicas de produção e circulação do conhecimento científico.

Eixo VI - Práticas Pré-Profissionalizantes

Aprendizagem em serviços como experiência de integração entre teoria e prática de natureza processual e aumento gradativo de complexidade em diferentes contextos de atuação do psicólogo.

Ademais, a comunidade, pela via da participação discente, avalia, acompanha e propõe alternativas em encontros semestrais, denominados Conselhos de Série, configurados como reuniões, que contam com a presença da coordenação de curso, representantes docentes e discentes do semestre e da supervisão pedagógica. Os encontros asseguram um movimento acadêmico democrático e produtivo ao fluxo do semestre em curso.

No campo da estruturação dos componentes curriculares, onde se coloca a singularidade do Projeto Pedagógico, professores e estudantes têm o desafio de construir um espaço coletivo de prática entre os componentes de natureza teórica e se realizam em níveis crescentes de complexidade ao longo do curso. A partir do primeiro semestre, o estudante é inserido em diferentes contextos de atuação do psicólogo, com o objetivo de desenvolver gradualmente competências e habilidades próprias ao desempenho da profissão. A experiência de inserção nesses contextos se dá em três níveis, com objetivos diferenciados: Práticas interdisciplinares, Internato, Estágio Específico.

\section{Práticas Interdisciplinares (Estágio Básico)}

Configura-se como campo de prática interdisciplinar na qual o estudante pode colocar em movimento o conteúdo dos componentes curriculares do semestre, de forma a estabelecer uma relação entre eles, durante os seis primeiros semestres do curso. Nesse âmbito, o estudante desenvolve atividades solidárias de natureza educacional, voltadas à promoção da saúde de diferentes pessoas e comunidades. 
Essa experiência está contemplada nas DCNs a partir da concepção de Estágio Básico e, no projeto de formação em Psicologia da Bahiana, constitui-se como componentes curriculares, denominados Técnicas e Práticas de Investigação em Psicologia I, II, III, IV, V e VI. Ao longo dos seis primeiros semestres realizam-se a partir dos Projetos de Extensão no Distrito Sanitário em que a instituição se insere, no Ambulatório Docente Assistencial da Bahiana (ADAB), em unidades básicas de saúde, creches e escolas (ensino fundamental e médio), vinculadas à estratégia do Programa de Saúde da Família (PSF) ou em Organizações não Governamentais (ONGs), nas quais a instituição realiza parcerias de pesquisa.

Na proposta didática, o Estágio Básico está associado aos temas de estudo que envolvem os componentes curriculares do semestre. Essa formatação constitui um novo desafio, também, para os professores, pois exige que se organizem sistematicamente no coletivo e sustentem um diálogo com o propósito de avaliar e, ao mesmo tempo, garantir a efetividade das atividades interdisciplinares. Sob a tutoria de, pelo menos um professor, os estudantes, semanalmente, desenvolvem atividades em espaços próprios à ação do psicólogo. Essas ações visam o desenvolvimento de habilidades procedimentais como as capacidades de realizar observação, entrevista, registros e aplicação de instrumentos de investigação e pesquisa em Psicologia.

Ao longo do semestre, os participantes têm a responsabilidade de produzir, no mínimo, uma atividade de retorno para a comunidade ou instituição onde a experiência se realizou. As atividades possuem caráter avaliativo e são desenvolvidas de forma interdisciplinar, o que favorece a interseção de vários componentes curriculares do semestre. Variando com o semestre e com o perfil do grupo, as atividades produzidas podem contemplar ações de educação ou promoção de saúde. Essas ações constituem-se a partir da demanda da comunidade ou instituição beneficiária.

\section{Internato}

A experiência acadêmica sob a forma de internato realiza a proposta de aprender-arefletir-fazendo. Consiste em vivência de transição que tem como propósito o desenvolvimento gradual das competências e habilidades básicas ao desempenho da profissão, na perspectiva do profissional de saúde generalista. A transição refere-se a uma situação de ação com relativa 
continuidade que garante aos alunos viverem situações diversas em determinadas instituições de trabalho. Esse vínculo permite uma visão generalista, sem prejuízo para o aprofundamento de demandas que sejam mais compatíveis com determinadas formações ou desejos que se processam no âmbito do curso e encaminham para uma especialização ou uma área de concentração de estudos. Trata-se de uma experiência absolutamente rica em apresentação da realidade, uma vez que qualquer situação concreta é hiper real, maior que qualquer previsibilidade projetada, que possibilita ao estudante conhecer as ênfases oferecidas pelo curso. Essa dinâmica estimula a atitude de busca e pesquisa, tanto no corpo discente como docente, fertilizando um ambiente acadêmico frutífero em debate, pesquisa e circulação do conhecimento.

A experiência, como está desenhada, possibilita ao estudante conhecer dois campos de prática da Psicologia: saúde e trabalho, ênfases oferecidas pelo curso, mas que se realizam em diferentes contextos de prática. Dessa forma, espera-se oferecer ao estudante um olhar fidedigno sobre o campo formativo, garantindo uma experiência generalista, evitando a especialização precoce, como frequentemente ocorre em um currículo tradicional, cheio de teorias, apresentadas de forma fragmentada em disciplinas que muitas vezes não conversam entre si. Ao contrário, o internato não apresenta a fronteira disciplinar para análise, mas se constitui numa paisagem real com todas suas implicações de referências múltiplas e contraditórias. Assim, é possível ao estudante ter acesso ao trabalho do psicólogo como promotor de saúde e qualidade de vida, independentemente do contexto de saúde ou trabalho.

Os internatos são componentes curriculares, organizados numa modalidade didática que pressupõe a observação da prática, a discussão de casos reais, desenvolvimento de ações, sob supervisão de tutores, que acompanharão, no máximo, 20 alunos por turma.

Os internatos acontecem no $7^{\circ}$ e $8^{\circ}$ semestres e cumprem um calendário acadêmico diferente dos semestres anteriores, pois não pressupõem férias no mês de julho, nem semana de descanso. Após uma semana de preparação inicial, o estudante é inserido em um dos três cenários de prática oferecidos e nele permanecerá por 10 semanas, onde deverá cumprir, no mínimo, 198 horas semestrais, em cada um dos três campos oferecidos, sob a supervisão de um tutor.

Os cenários de prática - unidades de saúde, escolas, comunidades ou organizações - estão alimentados por projetos de intervenção desenvolvidos por um professor ou por um grupo de professores que acolhem os estudantes e possibilitam que os conteúdos teórico-práticos, 
relacionados aos campos de saúde e trabalho, sejam assegurados ao estudante até o final da $10^{\mathrm{a}}$ semana. Ao final de cada período, os estudantes são reunidos para aprofundar os estudos referentes às atividades desenvolvidas, integrando a experiência. Os alunos são avaliados processualmente e produzem um relatório analítico, ultrapassando os princípios da descrição para memória da instituição e produção de um conhecimento relacionado ao trâmite da graduação.

Nessa fase do curso, o estudante participa/desenvolve ações de promoção, proteção, prevenção e diagnóstico, de tratamento ou intervenção, na condição de estar ao lado do professor/tutor. Entende-se que os estudantes, após três anos de curso, possam dominar os conhecimentos técnico-científicos inerentes à matriz bio-psico-social subjacente à prática do psicólogo, assim como competências individuais e coletivas básicas que lhes permitem estar aptos à formação em serviço, com a oportunidade de articular os conhecimentos adquiridos inseridos em um contexto profissional.

A experiência permite ao estudante construir, de forma progressiva, independência e segurança para articular a passagem do papel de estudante para o de profissional, integrando saberes, habilidades e competências assim como favorecer a escolha mais consciente por uma das ênfases oferecidas pelo curso no estágio específico.

\section{Estágio Específico}

Enquanto componente curricular do processo de formação acadêmica, os estágios específicos acontecem no $9^{\circ}$ e $10^{\circ}$ semestres. Eles estão regulamentados pelas leis de Estágio do Ministério do Trabalho e, no curso de Psicologia, são desenvolvidos em diferentes contextos de acordo com uma das ênfases escolhidas. Esses estágios permitem ao estudante experimentar a práxis no mundo laboral, participando e intervindo de forma a integrar as habilidades e competências desenvolvidas ao longo do curso, acompanhados por um supervisor especialista com carga horária mínima da instituição de 20 horas semanais.

A supervisão dos estágios específicos é dimensionada com uma carga horária de oito horas semanais, o que permite ao supervisor encontrar-se semanalmente com seu grupo de estagiários para quatro horas de atividades teóricas e quatro de supervisão e orientação de casos específicos. Também contempla a visita ao local de estágio do estudante, quando for 
desenvolvido fora das dependências da instituição e atendimentos individuais, quando necessário. Cada supervisor tem, no máximo, dez estagiários e, no mínimo, quatro por semestre letivo.

As sessões de supervisão, assim como as atividades diárias do estudante são registradas no diário de campo, prontuário ou relatórios, fichas de acompanhamento, de forma que possam ser avaliadas a qualquer momento. A estrutura avaliativa envolve a avaliação pelo supervisor, pelo grupo e a autoavaliação.

O estágio específico deve capacitar o estudante nos domínios fundamentais e nas ênfases: saúde e trabalho

O sistema de avaliação está pautado nos mesmos princípios norteadores da prática educativo-pedagógica do curso e, portanto, privilegia uma prática avaliativa reflexiva e investigativa, contemplando compreensão, entendimento, consciência crítica, exercícios de mediação, avaliações intermediárias e variados instrumentos de avaliação como critérios norteadores do processo. São trabalhados os domínios cognitivo, procedimental e atitudinal que se configuram nas dimensões do saber, saber fazer e saber ser.

A avaliação do desempenho e rendimento escolar observa os dispositivos legais nacionais e as determinações regimentais. A média de curso em cada componente curricular é obtida levando-se em conta a média aritmética ou ponderada das notas atribuídas pelos diversos instrumentos e atividades. A nota é expressa em grau numérico de 0,00 a 10 (zero a dez). Para ser aprovado o aluno deve obter média de curso igual ou superior a 7,00, caso em que a média final será igual à média de curso. O aluno que obtenha média de curso inferior a 7,00 e superior a 1,67 será submetido a um exame final, sendo que a média final deve ser igual ou superior a 5,00 obtida entre a média de curso, com peso 06 e a nota atribuída ao exame final, com peso 04.

O curso vem estimulando a discussão das provas intercomponentes curriculares, feita em conjunto por grupos de professores, assim como pelos alunos e professores em algumas situações, como outro momento de aprendizagem e, em especial, nas avaliações das clínicas setoriais e integradas, a devolução é parte essencial do processo. A avaliação do desempenho escolar incide sobre a frequência e o aproveitamento.

O ingresso principal no curso faz-se por meio de classificação obtida em processo seletivo (vestibular) para preenchimento das vagas existentes, por candidatos que tenham concluído o 
curso de ensino médio ou equivalente e por alunos regulares de outras instituições que venham a requerer transferência. A EBMSP tem dois processos seletivos:

O processo seletivo que visa ao preenchimento de vagas iniciais do curso de graduação oferecido é denominado Processo Seletivo Formativo. As propostas de reformulações curriculares com ênfase na humanização e integralidade no cuidado em saúde têm-se configurado uma alternativa para enfrentar criativamente a crise que se instalou nesse campo da educação do profissional de saúde. Na perspectiva de uma educação transformadora, a instituição modificou o sistema de seleção para ingresso em seus cursos e agregou ao seu moderno projeto pedagógico, um processo seletivo formativo coerente com suas mudanças curriculares.

O Processo Formativo Seletivo está baseado nos referenciais de metodologias ativas, refere-se a uma experiência avaliativa inovadora aplicada ao exame de vestibular, que agrega a um sistema classificatório - prova de conhecimentos gerais - uma experiência formativa discussões, reflexões pertinentes à prática profissional e atividades de socialização e integração referentes a habilidades interpessoais. Esse processo seletivo insere o estudante numa experiência de aprendizagem que estimula a reflexão sobre a futura profissão, valores éticos e humanos, considerados necessários à constituição identitária do profissional de saúde e se organiza da seguinte forma:

$1^{\text {a }}$ Fase: Avaliação de Conhecimentos Gerais Contemporâneos (eliminatória)

$2^{a}$ Fase: Dividida em dois momentos

$\boldsymbol{1}^{\circ}$ Momento - Vivencial com 60 minutos cada

- Dinâmica de Grupo

- Vivência Profissional

- $\quad$ Exibição de Filme

\section{$2^{a}$ Momento - Provas}

- $\quad$ Redação (Proposta de construção de um texto discursivo); 
- Avaliação com questões discursivas de ciências naturais, linguagem e ciências humanas.

Esse novo modelo de formação focaliza a capacitação e habilitação dos estudantes para o mundo e se contrapõe ao antigo modelo de vestibular que privilegiava a memorização de conceitos, sendo substituído por um processo avaliativo que leva em conta o raciocínio crítico e a lógica, bem como a capacidade do candidato de gerar novas soluções, estimulando sua criatividade. Além disso, permite ao estudante vivenciar a prática da atuação do psicólogo de forma a dar maior segurança frente a sua escolha.

No curso de Psicologia, as Atividades Complementares são consideradas de natureza acadêmica formal da graduação, de caráter obrigatório, constituindo-se em um espaço curricular para que os alunos desenvolvam projetos ou programas relacionados com a consolidação de conhecimentos e domínios téorico-práticos necessários à sua formação e ao desempenho profissional, concomitantes à realização do curso. Entende-se por atividades de natureza teóricopráticas aquelas que integram o saber acadêmico à prática profissional, possibilitando o aprimoramento de habilidades e competências necessárias ao futuro desempenho das atividades profissionais. Assim, as Atividades Complementares têm natureza formativa e estabelecem uma relação de suporte à estrutura curricular do curso.

\section{CONSIDERAÇÕES FINAIS}

Este trabalho apresenta uma proposta curricular inovadora, pois subverte a lógica histórica de formação de psicólogos, que sempre esteve focada na formação teórica reflexiva.

O caráter inovador dessa proposta está dado na forma como se estrutura a lógica formativa. Amplia-se e antecipa-se o espaço para a formação em serviço, utiliza-se de metodologias ativas de forma sistematizada focando o desenvolvimento das competências conceituais e procedimentais, mas oferece uma atenção especial às competências atitudinais por considerar que, na psicologia, o sujeito é instrumento do seu próprio trabalho e isso precisa estar incluído no processo formativo. 
A proposta aqui apresentada põe, no foco das reflexões sobre a formação do psicólogo, o lugar da instituição de ensino na produção sistemática de conhecimento científico, assim como de sua responsabilidade na constituição identitária da profissão. Dá então destaque ao trabalho formativo que desassocia teoria de prática, pensamento de ação, ideologia de linguagem, ensino e aprendizagem, conforme ensinou Paulo Freire.

É importante destacar que, agregada a essa proposta, dois importantes elementos dão suporte ao projeto. O primeiro é um trabalho voltado para a formação e valorização do professor, tanto no que se refere às condições de trabalho, capacitação técnica, mas também com especial estímulo à produção intelectual sobre sua prática docente. O segundo é o incentivo à pesquisa científica, organizado em programas de iniciação científica e foco na circulação do conhecimento.

O desafio constituído é de formar psicólogos, como profissionais de saúde, o que significa estar apto a fazer e pensar psicologia, assim como para cuidar de sujeitos e organizações em diferentes contextos e a responder de forma ética, solidária, empática, desprovido de preconceito de qualquer natureza. No processo de formação em serviço, o estudante é estimulado a exercitar e incorporar habilidades e competências gerais nas áreas de saúde e pesquisa, de forma a compreender o fenômeno psicológico em suas interfaces com os fenômenos biológicos, educacionais, socioculturais, organizacionais e, sempre que possível, trabalhando em estruturas interdisciplinares.

Dessa forma, o curso está estruturado de forma a assegurar uma formação básica pluralista e de atuação generalista, oferecendo ao aluno o acesso a diferentes teorias, áreas de conhecimento, métodos de investigação, pesquisa e técnicas que constituem áreas de conhecimento da psicologia, de forma que possa elaborar uma análise crítica e atual das questões, sistemas e técnicas pertinentes à área, respeitando a diferença entre eles.

\section{REFERÊNCIAS}

1. Brasil. Ministério da Educação, Conselho Nacional de Educação, Câmara de Educação Superior (BR). Resolução $n^{\circ}$ 8, Institui as Diretrizes Curriculares Nacionais para os cursos de graduação em Psicologia (7 maio, 2004) [Internet]. DOU (Brasília, DF). 200418 maio:Seção 
1:16-7 [citado 30 maio 2012]. Disponível em: http://portal.mec.gov.br/ index.php?option=com_docman\&task=doc_download\&gid=7690\&Itemid=>

2. Bardagi MP, Bizarro L, Andrade AMJ, Audibert A, Lassance MCP. Avaliação da formação e trajetória profissional na perspectiva de egressos de um curso de psicologia. Psicol Cienc Prof. 2008;28:304-15.

3. Machado, Lucília R. de Souza. A institucionalização da lógica das competências no Brasil. Pro-Posições, Campinas, Editora da Unicamp, 2002:131:92-110.

4. Santos FMS, Jacó-Vilela AM. O psicólogo no hospital geral: estilos e coletivos de pensamento. Paidéia 2009;19:189-97.

5. Pereira O, Almeida T. A formação médica segundo a pedagogia da resistência. Interface Com Saúde Educ. 2004;9:69-79.

6. Grosseman S, Patrício ZM. Do desejo à realidade de ser médico: a educação e a prática como processo contínuo de construção individual e coletiva. Florianópolis: UFSC; 2004.

7. OMS 1984 OMS (Organización Mundial de la Salud), Accidentes del Tráfico en los Países en Desarrollo. Serie de Informes Técnicos 703. Ginebra: WHO. 1984.

8. Josso MC. Experiências de vida e formação. São Paulo: Cortez; 2004.

9. Lima-Gonçalves E. Médicos e ensino da medicina no Brasil. São Paulo: USP; 2002.

10. Hahn MS. Estudos da clientela de um programa de atenção em saúde mental junto ao estudante universitário de São Carlos [dissertação]. [Campinas]: Faculdade de Ciências Médicas da Universidade Estadual de Campinas, 1994.

11. Ninin, Maria Otilia Guimarães. Pesquisa na escola: que espaço Ã@ esse? O do conteudo ou o do pensamento critico?. Educ. rev. [online]. 2008, n.48 [citedê 2012-08-16], pp. 17-35 . http://www.scielo.br/scielo.php?script=sci_arttext\&pid=S010246982008000200002\&lng=en\&nrm=iso. ISSN 0102-4698.Â http://dx.doi.org/10.1590/S010246982008000200002 .

12. Organização das Nações Unidas para a Educação, a Ciência e a Cultura (Unesco). Conferência Mundial sobre o Ensino Superior. Tendências da educação superior para o século XXI; 1998; Paris, França. Brasília: Unesco; 1999.

13. Cruz RM, Schultz V. Avaliação de competências profissionais e formação de psicólogos. Arq Bras Psicol. 2009;61:117-27.

14. Perrenoud P, Thurler MG, de Macedo L, Machado NJ, Allessandrini DC. As competências para ensinar no século XXI: a formação dos professores e o desafio da avaliação. Porto Alegre: Artmed; 2002. 
15. de Amorim VM, Castanho ME. Por uma educação estética na formação universitária de docentes. Educ Soc. 2008;29:1167-84.

16. Instituto Brasileiro de Geografia e Estatística (IBGE). Sinopse do censo demográfico 2010 Brasil [Internet]. [citado 25 maio 2012]. Disponível em:

http://www.censo2010.ibge.gov.br/sinopse/ 